\title{
La canción popular en la Italia del siglo XX: una visión antagónica de la historia
}

\author{
Sabina LONGHITANO \\ Universidad Nacional Autónoma de México
}

\begin{abstract}
Quiero dedicar este trabajo a la memoria de mi abuelo, el teniente Ezio Piazza, quien fue uno de los soldados mandati al macello en Grecia: su batallón, estacionado en Patrás a lado de un enorme despliegue de fuerzas alemanas, decidió entregar las armas: todos los soldados fueron enviados a un campo de prisioneros en Alemania, donde estuvieron hasta abril de 1945.
\end{abstract}

El origen de la canción popular italiana se remonta al nacimiento de los vulgares, una gran variedad de dialectos derivados del latín vulgar. Las invasiones bárbaras que siguieron a la caída del Imperio romano de Occidente y las conquistas y reinos sucesivos llevaron en la música popular italiana influencias bizantinas, griegas, árabes, judías, pero también alemanas, francas, eslavas, normandas e hispánicas.

Posteriormente a los vulgares dialectales y regionales, nació una lengua literaria, cuyo proceso de fijación y codificación fue llevado a cabo por varias figuras de intelectuales cortesanos al principio de 1500, después de una gestación de casi tres siglos. Esta lengua literaria tomó como modelos la versión más culta del dialecto toscano (en particular la lengua del Canzoniere de Petrarca), el latín clásico canonizado por los humanistas y la lengua formal usada en las cortes italianas. La evolución de esta lengua literaria, que por siglos fue casi exclusivamente una lengua escrita, fue la base que el recién nacido estado italiano tomó para desarrollar la lengua italiana moderna.

A partir de 1860, fecha considerada por los historiadores como el punto de comienzo simbólico del capitalismo en Italia, empiezan a circular las primeras canciones populares en italiano y no sólo en los dialectos. Es una lengua sencilla, expresiva, matizada con vocablos regionales. Sin embargo, mucha gente en Italia la entiende, ya que las guerras - las coloniales primero y las dos guerras 
mundiales después - ven por primera vez a soldados provenientes de todas partes de Italia combatiendo y comunicándose entre sí.

Los movimientos socialista, anarquista y comunista encuentran en el canto popular un poderoso instrumento de difusión de sus ideas. Las canciones que circulaban entre ellos, muchas en italiano, desde Il feroce monarchico Bava y Le otto ore, hasta Correte giovanotti in Abissinia, Noi vogliamo l'uguaglianza, Viva viva il nostro Bresci y La lega (además de las tres canciones que presento a continuación), sirven de controcanto a las canciones patrióticas oficiales, propaganda retórica del nacionalismo, como La canzone del Piave, y del fascismo, como Giovinezza, Faccetta nera y Me ne frego.'

En el norte y en el sur se difunden siempre más los que han sido definidos por los etnomusicólogos como cantos sociales. ${ }^{2}$ Son cantos de protesta, de denuncia, de afirmación política, de contrainformación y propaganda, cantos que comentan los hechos histórico-sociales del momento, se burlan de los personajes políticos y de sus decisiones, llegando a desenmascarar, con su tajante ironía, las hipocresía de los poderosos.

En este artículo voy a presentar tres cantos populares que comentan hechos históricos relevantes del siglo XX, en particular el periodo que va desde el comienzo de la Primera Guerra Mundial hasta el final de la segunda. Son canciones en italiano, en un italiano popular cuya sintaxis está todavía ligada a los dialectos, el italiano hablado en las trincheras de la Primera Guerra Mundial, en las montañas donde combatían los partisanos (partigiani) en la segunda, en los círculos políticos socialistas, anarquistas y comunistas que entraron en clandestinidad en la era fascista.

Para el pueblo, desde siempre, la guerra significa muerte, desolación, miseria, inseguridad y hambre. A pesar de los discursos vacíos de los poderosos, que tratan de convencer de la necesidad de la guerra, de su inevitabilidad, de su justicia, de la defensa de valores morales o éticos superiores como la patria, la democracia, la libertad, los cantos como los que vamos a presentar, junto con muchos otros, comunican con claridad, expresividad y gran fuerza de imágenes, la posición de los pobres, del pueblo, ante la tragedia de la guerra.

'Una excelente antología de canciones populares italianas, en dialecto y en italiano, es la editada por G. Vettori (1975), Il folk italiano. Canti e ballate popolari. Véase también G. L. Falabrino (1994), I comunisti mangiano bambini. La storia dello slogan politico, y el artículo de I. Principe, "La storia del novecento italiano raccontata dalle canzonette".

${ }^{2}$ G. Bosio (1998: 57-63). También indispensable para cuestiones de método, C. Bermani (1999). 


\section{Gorizia}

Una de las canciones antimilitaristas más elocuentes y significativas de todos los tiempos es Gorizia, que hace un recuento emocional y político al mismo tiempo de la batalla de Gorizia, ciudad que Italia le disputó a Austria en 1916. Según cálculos oficiales, en la batalla para conquistar la ciudad de Gorizia, que duró del 5 al 10 de agosto de 1916, murieron alrededor de noventa mil soldados, cincuenta mil italianos y cuarenta mil austriacos. La ciudad quedó finalmente en manos italianas. La versión que aquí se presenta ha sido recopilada por el investigador Cesare Bermani, de un testigo que afirmó haberla escuchado de las tropas que conquistaron Gorizia el 10 de agosto de $1916 .^{3}$

1 La mattina del cinque d'Agosto

2 Si muovevano le truppe Italiane

3 Per Gorizia le terre lontane

4 E dolente ognun si partì.

5 Sotto l'acqua che cadeva a rovesci

6 Grandinavano le palle nemiche

7 Su quei monti colline gran valli

8 Si moriva dicendo così:

9 Oh Gorizia tu sei maledetta

10 Per ogni cuore che sente coscienza

11 Dolorosa ci fu la partenza

12 E il ritorno per molti non fu.

13 Oh vigliacchi voi che ve ne state

14 Con le mogli sui letti di lana

15 Schernitori di noi carne umana

16 Questa guerra ci insegna a punir.
La mañana del cinco de agosto

Se movían las tropas italianas

Para Gorizia las tierras lejanas

Y cada uno, dolido, partió.

Bajo el agua que llovía a cántaros

Granizaban las balas enemigas

En los montes, cerros, grandes valles

Se moría diciendo así:

Oh Gorizia, tú eres maldita

Por cada alma que tiene conciencia

Dolorosa nos fue la partida

Y para muchos no hubo regreso.

Oh, cobardes, ustedes que se quedan

Con sus esposas en camas calientes

Escarnecedores de nosotros, carne humana

Nos enseña esta guerra a castigarlos.

${ }^{3}$ La letra de la canción, acompañada por estas notas históricas, se encuentra en el sitio web http://www.vocidimezzo.it. El coro de canto popular Le Voci di Mezzo, dirigido por Angelo Pugolotti, con sede en Milán, se dedica al descubrimiento y valoración de la cultura popular y la memoria histórica "de los campesinos, de los obreros, de los excluidos, de los explotados, de los subversivos y de los resistentes de cada tiempo y lugar". El hecho de haber cantado con este grupo en otros tiempos y poder ahora recurrir a su sitio web han sido una fuente preciosa de inspiración e información para el presente trabajo. Las traducciones al español son mías. 
17 Voi chiamate il campo di onore

18 Questa terra di là dei confini

19 Qui si muore gridando: "Assassini

20 Maledetti sarete un di".

21 Cara moglie che tu non mi senti

22 Raccomando ai compagni vicini

23 Di tenermi da conto i bambini

24 Che io muoio col suo nome nel cuor

25 Traditori signori ufficiali

26 Che la guerra l'avete voluta

27 Scannatori di carne venduta

28 E rovina della gioventù

29 Oh Gorizia tu sei maledetta

30 Per ogni cuore che sente coscienza

31 Dolorosa ci fu la partenza

32 E il ritorno per molti non fu.
Ustedes llaman "el campo de honor"

A esta tierra más allá de las fronteras

Aquí se muere gritando: "Asesinos,

Algún día malditos serán"

Querida esposa, que tú no me escuchas

Les suplico a los compañeros cercanos

Que me cuiden a mis niños,

Que muero con su nombre en el corazón.

Traidores señores oficiales,

Que la guerra ustedes la quisieron,

Carniceros de carne vendida

$Y$ ruina de la juventud

O Gorizia, tú eres maldita

Por cada alma que tiene conciencia

Dolorosa nos fue la partida

Y para muchos no hubo regreso.

En la misma fuente citada anteriormente encontramos:

En 1964, el Nuovo Canzoniere Italiano, una agrupación de investigadores y ejecutores de música popular, presentó esta canción en el Festival dei due Mondi de Spoleto, en el espectáculo Bella ciao, dedicado a la guerra. En el momento en que Michele Straniero entonó la penúltima estrofa, Traditori, signori ufficiali, dos oficiales del ejército presentes en la sala protestaron con fuerza e intentaron interrumpir el espectáculo. Todo el grupo del Nuovo Canzoniere Italiano fue denunciado por ofensa a las fuerzas armadas.

Lingüísticamente, esta canción presenta varios puntos de interés:

En la primera estrofa (1. 1-4) observamos un asíndeton (1.3, per Gorizia le terre lontane), donde sintácticamente haría falta una conjunción como "y", y el verbo partirsi (1.4, e dolente ognun si parti), popular por partire con dativo de interés. En la segunda estrofa observamos la metáfora de las balas enemigas que granizaban en medio de la lluvia (1. 5-6); éste me parece un ejemplo de revitalización de una catacresis, o metáfora muerta; normalmente, las balas "llueven", sin embargo, si ya está lloviendo (lo que hace la escena todavía más trágica y desesperada), las balas tienen que ser más fuertes, y por eso se 
describen como granizo. Hay también otro asíndeton a la 1.7 (su quei monti colline gran valli); además, la forma impersonal de la 1.8 , si moriva, que se alterna con la primera persona plural y a la primera singular en todo el canto, es típica de muchos dialectos del norte de Italia. ${ }^{4}$

En el estribillo (1. 9-10), el presente indicativo junto con la apóstrofe a la ciudad (Oh Gorizia, tu sei maledetta, 1. 9) tiene una gran fuerza asertiva. El subjuntivo es un modo más culto, menos inmediato del indicativo, y por eso muy poco usado en el italiano popular. En cambio, la maldición de la ciudad se declara con el indicativo, que le da una gran fuerza expresiva: Gorizia es una ciudad maldita por quienes entienden, por los que tienen conciencia de los hechos.

Además observamos el antítheton entre la partenza ("la partida", 1. 11) e il ritorno ("el regreso", 1. 12): la primera fue dolorosa, el segundo, sin embargo, no aconteció. La anáfora del verbo ser $(f u$, con el segundo término negado, non fu 1. 11-12), la oposición entre ci ("nos", "para nosotros", 1. 11) y per molti ("para muchos", 1. 12) y la posición en quiasmo de los dos términos opuestos (la partenza/il ritorno) refuerzan este antítesis.

En la tercera estrofa (1. 13-16) encontramos un anacoluto: en las primeras dos líneas hay una apóstrofe en segunda persona plural (Oh vigliacchi, voi che ve ne state 1. 13); en las dos líneas siguientes, la aposición de esta apóstrofe (1. 16, schernitori di noi) es el complemento directo de questa guerra ci insegna a punir, en posición invertida (anástrofe). Carne umana en esta estrofa se refiere a "nosotros", y es una aposición de tipo metonímico. También se nota la imagen estereotípica del rico, del poderoso, abrazado a su esposa en su cama caliente, con colchones y cobijas de lana (que metonímicamente se describe como letti di lana, "camas de lana"): un verdadero lujo para los pobres soldados que morían de frío en las trincheras.

Otra oposición muy fuerte se encuentra en la estrofa sucesiva, la cuarta (1. 17-20): en las primeras dos líneas se menciona explícitamente el discurso de los poderosos, apostrofados en segunda persona plural (voi, 1.17), quienes usan perífrasis vacías (il campo di onore, "el campo de honor", 1.17) para referirse a Gorizia, a una tierra que se encuentra fuera de las fronteras patrias (1. 18). Sin embargo, qui ("aquí", l. 19), en Gorizia, en il campo di onore, la gente muere. Otra vez un impersonal -y siempre con el verbo morir- para expresar la oposición (Voi chiamate / Qui si muore, ambos en posición fuerte, al principio de verso, 1.17 y 19) entre los responsables, que se señalan con voi (ustedes) y el pueblo, como un sujeto coral que muere reclamando a gritos la culpabilidad

\footnotetext{
${ }^{4}$ Esta forma está muy presente en los primeros cuentos de Italo Calvino, los que relatan la experiencia de la Resistenza partisana cuyo lenguaje está influido, especialmente en la sintaxis, por modos populares.
} 
de sus comandantes, su responsabilidad en la muerte de muchos inocentes en una guerra abstracta e incomprensible, por un campo di onore que ni siquiera es parte de Italia, que está más allá de sus fronteras. Y, por eso, algún día la historia reconocerá su responsabilidad y los maldecirá en el sentido proprio, etimológico de la palabra: se hablará mal de ellos.

Otro anacoluto se puede observar en la 1.21, ya que la estrofa empieza con una apóstrofe a la esposa (Cara moglie, che tu non mi senti), cuya relación con lo que sigue es sintácticamente poco clara, así como poco claro es el "que" polivalente, con una función de conexión poco definida, al que hay que dar un valor causal para salvar la coherencia del texto. Otro "que" polivalente se encuentra en la 1.24 (che io muoio col suo nome nel cuor) en la misma estrofa, que es la más dificil de traducir e interpretar, ya que, aunque la función causal sea la más plausible, sin embargo no deja muy clara la relación entre esta oración y la precedente. La asignación de referente de suo ("su") en la misma línea no es banal: por el sentido y por la posición debería de referirse a bambini ("niños"), cosa plausible ya que el italiano popular (así como el español) no distingue entre el posesivo de tercera persona singular y plural (en italiano culto, en cambio, el primero se expresa con suo/sua y el segundo con loro). Sin embargo, también se podría referir a moglie y bambini, con un concordancia ad sensum.

La última estrofa (1.25-28) presenta también problemas sintácticos, ya que la oración principal es una frase nominal, sin verbo: se trata de un duro anatema hacia, en este caso, los oficiales, símbolo y encarnación del poder, representantes de quienes la guerra la quisieron por sus intereses personales, y quienes están dispuestos a vender a las personas para mandarlas a morir, y convertirse, así, en sus carniceros.

Hay varios puntos en común de esta estrofa con la cuarta: el hecho de que las dos están construidas sobre frases nominales, como las del apóstrofe inicial (Oh vigliacchi, voi che ve ne state, 1. 13, y Traditori, signori ufficiali, 1.25), la metáfora durísima de la guerra como carnicería, con la repetición de carne, en paralelismo, acompañada en los dos casos de adjetivos con la misma estructura, en homoteléuton (schernitori di noi carne umana, 1. 15, scannatori di carne venduta, 1. 27). Este homoteléuton se repite, con una rima interna traditori/ scannatori (1.23 y 25). La carne humana de la que se hacía escarnio en la cuarta estrofa es ahora venduta ("vendida", 1.27), y esto representa una acusación todavía mayor: la de tener intereses económicos personales en la guerra, de mandar al pueblo a la masacre por lucro. Además, la metonimia de la carne tiene muchas más implicaciones que simplemente "gente", o "personas" o "seres humanos": la carne es frágil, es mortal, puede ser scannata ("masacrada, degollada") y vendida después. Otra metonimia, la de "juventud", le da al enunciado un respiro más amplio y universal. 


\section{Bella ciao}

El 8 de septiembre de 1943, en plena Segunda Guerra Mundial, el radio da la noticia de la firma del armisticio entre Italia y los aliados por parte del rey Vittorio Emanuele y del jefe del gobierno, el mariscal Badoglio (de quien hablaré a propósito de la siguiente canción). Por tres días el ejército italiano queda sin mando, rodeado por los alemanes, y en muchos casos los batallones italianos que se niegan a rendirse a los alemanes son masacrados por completo. El sur de Italia, hasta Nápoles, está en manos aliadas, el norte es ocupado por los alemanes. También los italianos están divididos. Por un lado están los que apoyan al fascismo, o lo temen demasiado para oponerse a sus abusos, o son parte de la burocracia fascista, o de sus milicias, los tristemente célebres squadristi, paramilitares con funciones de policía y de orden público. Por otro lado, la oposición socialista y comunista se reorganiza en Francia, y empieza la guerrilla de los partisanos, quienes deciden entrar en clandestinidad y refugiarse en las montañas para combatir a los alemanes y favorecer la llegada de los aliados.

A este momento trágico de la historia italiana se refiere Bella ciao, la canción que sigue.

1 Stamattina mi sono alzato

2 O bella ciao bella ciao bella ciao ciao ciao

3 Stamattina mi sono alzato

4 E ho trovato l'invasor

5 O partigiano portami via

6 O bella ciao, bella ciao, bella ciao ciao ciao

7 O partigiano portami via

8 Che mi sento di morir

9 E se io muoio da partigiano

10 O bella ciao, bella ciao, bella ciao ciao ciao

$11 \mathrm{E}$ se io muoio da partigiano

12 Tu mi devi seppellir

13 E seppellire lassù in montagna

14 O bella ciao, bella ciao, bella ciao ciao ciao

15 E seppellire lassù in montagna

16 Sotto l'ombra di un bel fior
Esta mañana me levanté

Adiós linda, adiós, adiós,

Esta mañana me levanté

$\mathrm{Y}$ encontré al invasor

Oh partisano, llévame contigo

Adiós linda, adiós, adiós,

Partisano, llévame contigo

Porque quiero morir

Y si me muero como un partisano

Adiós linda, adiós, adiós,

Si me muero como un partisano

Tú me tienes que sepultar

Y sepultar allá en los montes

Adiós linda, adiós, adiós

Sepultar allá en los montes

Bajo la sombra de una linda flor 
17 E le genti che passeranno

18 O bella ciao, bella ciao, bella ciao ciao ciao

19 E le genti che passeranno

20 Mi diranno che bel fior

21 E questo è il fiore del partigiano

22 O bella ciao, bella ciao, bella ciao ciao ciao

23 E questo è il fiore del partigiano

24 Morto per la libertà

25 E questo è il fiore del partigiano

26 Morto per la libertà
Y las gentes que pasarán

Adiós linda, adiós, adiós

Las gentes que pasarán

Me dirán: "Qué linda flor"

Ésta es la flor del partisano

Adiós linda, adiós, adiós

Ésta es la flor del partisano

Muerto por la libertad.

Ésta es la flor del partisano

Muerto por la libertad

A pesar de que ésta se puede considerar la canción de la Resistencia más famosa en Itatia y en el mundo, en realidad Bella ciao alcanzó una gran difusión después de la liberación. Fue muy difundida especialmente a partir de los años '60, cuando [el cantautor y actor N. del T.] Giorgio Gaber [...] la presentó en un espectáculo de televisión [...] En la misma época fue grabada por Yves Montand y propuesta en el espectáculo del Nuovo Canzoniere Italiano, titulado Bella ciao, en el Festival dei due Mondi de Spoleto de 1964, que suscitó muchas polémicas. ${ }^{5}$

Lingüísticamente, esta canción presenta muchas menos irregularidades y anacolutos que la precedente: durante los veinticinco años que las separan, la alfabetización habia hechos grandes pasos en Italia, lo que fue un logro indiscutible del gobierno fascista, que utilizó la escuela primaria y secundaria también como instrumento de propaganda para adoctrinar a los jóvenes sobre la ideología fascista. El único problema de interpretación que encuentro en esta canción está en la l. 8, ya que esta oración tiene dos interpretaciones posibles. La locución de registro coloquial mi sento di+infinitivo (di morir) tiene, en este contexto, el significado de "estar listo para algo, desear, tener el valor para algo". Un caso de sintaxis popular, es el de la 1. 17: en italiano culto, así como en español, normalmente, la palabra gente ("gente") se usa en singular y es un plural colectivo ad sensum, aunque la concordancia del verbo tiene que ser en singular; por ej.: la gente esprime la propria opinione ("la gente expresa su opinión"). Sin embargo, en muchos dialectos, se explicita el plural colectivo transformándolo en plural morfológico como en este caso y concordándolo con

${ }^{5}$ También la letra de esta canción y esta nota histórica se encuentra en el sitio web mencionado. La traducción es mía. 
el verbo en plural: el efecto expresivo es el de ensanchar la mirada, la cantidad y calidad de estas "gentes", como si fueran gentes que provienen de muchos lados, pueblos y culturas distintas, como se usa, por ejemplo, en los Evangelios.

El texto tiene un punto de vista personal, ya que está en primera persona singular; sin embargo, el narrador cuenta una experiencia común a muchos partisanos: despertar con la conciencia de que su país ha sido ocupado y decidir defenderlo con las armas. La estructura es simple y lineal, con gran presencia de anáforas: en cada estrofa, la tercera línea repite la primera, y la segunda es siempre igual, representando el refrán (o bella ciao, bella ciao, bella ciao ciao ciao). En muchos casos, la estrofa comienza retomando el final de la precedente, lo que es un típico recurso de la poesía italiana popular, creando efectos de anáforas y políptotos: 1.8 morir, 1.9 muoio; 1.12 seppellir, 1.13 seppellire; for (1.20), y fiore (1. 21); además, las palabras partigiano y fiore son anáforas frecuentes en todo el texto.

Métricamente, se trata de una estructura bastante regular y típica donde el refrán, que, como hemos dicho arriba, está incrustado en cada estrofa, es un dodecasílabo con acentos 4-7-10; el primer y el tercer verso de cada estrofa (que son iguales) son novenarios o decasílabos, con cesura respectivamente después de la cuarta o en la quinta sílaba, y, en el caso del decasílabo, con la primera sílaba átona, lo que crea hemistiquios simétricos o casi simétricos. El último verso de cada estrofa es un octosílabo agudo. La última estrofa presenta un estribillo final no obligatorio, sino al gusto de quien lo canta.

En el texto hay motivos de la canción narrativa "Fior di tomba" ("Flor de tumba"), de la que se retoma la importancia que se da a las flores como gesto de memoria de los vivos hacia los muertos. La estructura y la música derivan de una balada de niños difundida en área veneciana, y que está inspirada a su vez en una balada, llamada "La bevanda sonnifera" ("La bebida somnifera"). Hay una desgarradora versión de Bella ciao con la letra adaptada por las mondine, o sea las mujeres que trabajaban en la pizca del arroz, en la que se cuentan los sufrimientos de este durísimo trabajo.

\section{La Badoglieide}

La siguiente canción que presento, titulada La Badoglieide, es, al contrario de las otras dos, una narración fuertemente satírica, irónica y humorística, en la que, con un lenguaje muy vivaz y expresivo, se interpreta la carrera político-militar de un personaje de primer plano en la historia de esta época: el mariscal Pietro Badoglio. Sobre las circunstancias de la composición de esta canción tenemos un testimonio del escritor de la Resistencia Nuto Revelli, quien relata: 
En una pausa muy corta del gran operativo [alemán, N. del T.] del abril 1944, en la noche entre el 25 y el 26, en una casa de montaña en un lugar cerca de Narbona, entre los valles Grana y Maira, ocho o nueve partisanos de la cuarta brigada Giustizia e Libertá (Il sector), hablan, tararean, cantan. Sobre la melodía muy pegadiza de la canción $E$ non vedi che sono toscano, nace la primera estrofa, luego, en colaboración colectiva, las demás y toda la canción. ${ }^{6}$

1 O Badoglio, Pietro Badoglio Ingrassato dal Fascio Littorio Col tuo degno compare Vittorio $\mathrm{Ci}$ hai gia rotto abbastanza i coglion.

2 Ti ricordi quand'eri fascista E facevi il saluto romano

Ed al Duce stringevi la mano

Sei davvero un gran bel porcaccion.

3 Ti ricordi l'impresa d'Etiopia

E il ducato di Addis Abeba

Meritavi di prender l'ameba

Ed invece facevi i milion.

4 Ti ricordi la guerra di Francia Che I'Italia copriva d'infamia Ma tu intanto prendevi la mancia E col Duce facevi ispezion.

5 Ti ricordi la guerra di Grecia E i soldati mandati al macello, E tu allora per farti piu bello Rassegnavi le tue dimission.
O Badoglio, Pedro Badoglio, Engordado por los fascistas Con tu digno compinche Vittorio Ya nos tienes hasta la madre.

No recuerdas cuando eras fascista $Y$ hacías el saludo romano $Y$ al Duce le estrechabas la mano Eres muy, pero muy marrano.

No recuerdas la hazaña de Etiopia Y el ducado de Addis Abeba Merecías enfermarte de amibas $\mathrm{Y}$ al contrario juntabas millones.

No recuerdas la guerra de Francia En que Italia se cubrió de infamia Pero tú te sacaste el pilón Con el Duce haciendo revisión.

No recuerdas la guerra de Grecia $\mathrm{Y}$ los soldados que mandaste al matadero $\mathrm{Y}$ tú entonces para lucirte, Decidiste darnos tu dimisión.

${ }^{6}$ Recuerdos y testimonio de Nuto Revelli, reportados por L. Mercuri y C. Tuzzi (1962: 76). Los editores citan también los nombre de los otros coautores de la canción, partisanos muy conocidos como Ivanoe Bellino, Alberto y Livio Bianco y Nino Monaco, entre otros. También esta información se encuentra en el sitio web http://www.vocidimezzo.it. La traducción es mía. 
6 A Grazzano giocavi alle bocce Mentre in Russia crepavan gli alpini Ma che importa, ci sono i quattrini E si aspetta la buona occasion.

7 L'occasione è arrivata

È arrivata alla fine di luglio

Ed allor, per domare il subbuglio, Ti mettevi a fare il dittator.

8 Gli squadristi li hai richiamati Gli antifascisti li hai messi in galera La camicia non era più nera Ma il fascismo restava il padron.

9 Era tuo quell'Adami Rossi Che a Torino sparava ai borghesi Se durava ancora due mesi Tutti quanti facevi ammazzar.

10 Mentre tu sull'amor di Petacci T'affannavi a dar fiato alle trombe Sull'Italia calavan le bombe E Vittorio calava i calzon.

11 I calzoni li hai calati Anche tu nello stesso momento Ti credevi di fare un portento Ed invece facevi pietà.

12 Ti ricordi la fuga ingloriosa Con il re, verso terre sicure; Siete proprio due sporche figure, Meritate la fucilazion.

13 Noi crepiamo sui monti d'Italia Mentre voi ve ne state tranquilli
En Grazzano jugabas a los bolos Cuando en Rusia morían los alpinos Mas ¿qué importa? Hay mucho dinero $Y$ se espera una buena ocasión.

La ocasión por fin ha llegado Ha llegado a finales de julio Cuando tú, para calmar el barullo Te pusiste a hacer de dictador.

A los escuadristas los reincorporaste A los antifascistas los metiste a la carcel Las camisas ya no eran negras Pero el fascismo siguió reinando.

Era tuyo aquel Adami Rossi Que en Turín disparó a los burgueses Si duraba aún por dos meses Todo el mundo mandabas matar.

Mientras tú sobre el amor de Petacci ${ }^{7}$ Te afanabas a tocar los clarines Sobre Italia bajaban las bombas Y Vittorio se bajaba el pantalón.

Te bajaste el pantalón Tú también en el mismo momento Creías estar haciendo un portento Sólo lástima lograste dar.

No recuerdas la fuga sin gloria Junto al rey, hacia tierras seguras Son ustedes dos tipos bien sucios Fusilados merecen morir.

En los montes nosotros reventamos $\mathrm{Y}$ ustedes se quedan tranquilos

\footnotetext{
${ }^{7}$ Claretta Petacci fue la amante de Mussolini hasta los últimos momentos de su vida, cuando los cuerpos de los dos, fusilados por los partisanos, fueron colgados de cabeza en Milano, en Piazzale Loreto, el 29 de abril de 1945.
} 
Ma non crederci tanto imbecilli

Da lasciarci di nuovo fregar.

14 No, per quante moine facciate State certi più non vi vogliamo Dillo pure a quel gran ciarlatano Che sul trono vorrebbe restar.

15 Se Benito ci ha rotto le tasche Tu, Badoglio, ci hai rotto i coglioni; Pei fascisti e pei vecchi cialtroni In Italia più posto non c'è.
No nos creas aún más imbéciles Para dejarnos joder otra vez.

No, por cuantas lisonjas nos hagan Den por cierto y a no los queremos $Y$ avísale a ese gran farsante Que en el trono quisiera seguir.

Si Benito nos tiene hasta el gorro Tú, Badoglio, nos traes hasta el huevo Para fascistas y viejos canallas En Italia ya no hay más lugar. ${ }^{8}$

El texto es dedicado a describir las hazañas de un personaje ilustre: el mariscal Pietro Badoglio. Los hechos salientes de su vida se representan de forma rápida e incisiva, como cuadros de un retablo, con un sabroso estilo vernáculo. La intención comunicativa es satírica: a través de una narración que da una interpretación del papel político de este personaje, se pronuncia un juicio político sobre él.

La melodía y la letra tienen muchos puntos en común con el corrido mexicano: como la del corrido, la música es sencilla y pegadiza, con el tiempo de vals tan típico de las melodías populares; muchas veces la misma melodía, que corresponde a una estructura métrico-silábica, se presta a ser adaptada a varias ocasiones, a diferentes contenidos.

Tratándose de una canción esencialmente narrativa, que se refiere a hechos históricos notorios en aquella época, me parece oportuno empezar resumiéndolos para proveer un contexto de interpretación más detallado y permitir al lector apreciar sus cualidades expresivas. La narración de los hechos conlleva su interpretación, implicando el reconocimiento de la intención satírica de los autores, quienes se autorrepresentan en el texto (estr. 13), como los que mueren en los montes para remediar a los errores irresponsables de los poderosos.

La carrera de Pietro Badoglio empieza en la Primera Guerra Mundial: en octubre de 1917 unos regimientos bajo su mando cedieron en Caporetto, contribuyendo al clima de alarma general que anticipó la verdadera derrota. Durante

${ }^{8}$ El texto de la canción presenta expresiones vulgares, típicas de un registro popular. Me parece que el uso del español estándar no las rendiría adecuadamente, así que decidí traducirlas utilizando los recursos expresivos del vernáculo de México, que es donde este trabajo ha sido escrito y presentado. 
el fascismo fue presidente del Consiglio Nazionale delle Ricerche (Consejo Nacional de Investigaciones), que servía para crear relaciones de clientelismo con el gobierno fascista (estr. 1-2).

En 1936, al mando de la guerra de Etiopía, conquistó la capital, Addis Abeba, en tan sólo seis meses, con un uso indiscriminado de gases venenosos y bombardeos. Badoglio fue uno de los que se enriquecieron en la aventura colonial italiana que, por lo demás, fue absolutamente estéril: una administración corrupta gastó dinero en "obras fascistas" que sólo servían de propaganda (estr. 3).

Badoglio fue jefe de estado mayor del gobierno fascista hasta 1940, cuando Mussolini asumió personalmente el mando, animado por la fácil victoria de Alemania en Francia, en donde participó también el ejército italiano. Mussolini estaba seguro de que la guerra acabaría pronto; al avisarle Badoglio sobre el riesgo de entrar en guerra, Mussolini respondió que "Sólo le servian unos miles de muertos para participar a las negociaciones de paz" (estr. 4). Por otro lado, la aventura en Grecia (octubre de 1941) fue el peor desastre militar de Italia en toda la guerra: después de pocos días, el ejército italiano ya estaba en plena retirada.

En este punto, Badoglio presentó su renuncia y se retiró en su pueblo natal, Grazzano (estr. 5-6). En enero de 1943, la mitad de los doscientos veinte mil soldados enviados por Mussolini a Rusia en 1941 habian sido masacrados, o capturados (estr. 6). En mayo, el ejercito italiano se rindió.

A finales de julio 1943, después de una serie de huelgas en las industrias del norte de Italia, del desembarque aliado en Sicilia y del bombardeo de Roma, el propio Gran Consejo fascista pone a Mussolini en minoría, con un programa de eliminación del Estado totalitario y reintegración del rey. Badoglio es nombrado presidente del Consejo (o sea, primer ministro), y Mussolini es arrestado (estr. 7).

Al gobierno de Badoglio se le conoce como "Los cuarenta y cinco días"; él, figura representativa del fascismo pero también de la autocracia monárquica, declaró ilegal al partido fascista pero no removió a sus funcionarios y burócratas, y mantuvo a la milicia fascista y la censura. Badoglio quería un gobierno conservador sin los fascistas, y por eso empezó una durísima represión, con muertos y heridos en cada manifestación popular de los movimientos antifascistas (estr. 8).

El 3 de septiembre de 1943, el nuevo gobierno italiano guiado por Badoglio concordó un armisticio con los aliados, y lo anunció a la población el 8 del mismo mes. Sin embargo, el ejército italiano no participó en el intento de ocupar Italia por parte de los estadounidenses ya que el rey y Badoglio dieron marcha atrás, pidiéndole a los aliados no atacar Roma. E1 9 de septiembre, el rey Vittorio Emanuele y Badoglio huyeron hacia el sur, dejando al ejército italiano sin mando: los alemanes aprovecharon la confusión, y ocuparon Roma y toda 
Italia hasta Nápoles, donde una insurrección popular los detuvo hasta la llegada de los aliados (estr. 10-11-12). ${ }^{9}$

El ejército italiano quedó en el caos más completo por tres días, hasta el 11 de septiembre. Cuando las órdenes llegaron, le pedían al ejército (regado por medio mundo, de África a Grecia) no tomar ninguna iniciativa y quedarse esperando, lo que implicaba el riesgo de ser atacados por los alemanes. No importaba: Badoglio mismo declaró que estaba dispuesto a sacrificar hasta medio millón de hombres para llevar a buen fin el armisticio y empezar a combatir contra los alemanes. La mayoría de las tropas italianas se resistieron unos días, luego se rindieron, y acabaron en campos de concentración para prisioneros en Alemania y Polonia. Los presidios de Corfú, Cefalonia y otras islas del mar Egeo, que se resistieron hasta al final, fueron exterminados en masa.

La fundación por parte de Mussolini de un "nuevo Estado republicano", la Repubblica di Salò, el 13 de septiembre, suscitó reacciones muy diversas, en favor o en contra, por parte de los generales a cargo de las tropas. Cabe destacar que los fascistas de Salò cantaban una versión modificada de esta canción, por su contenido antimonárquico y porque consideraban a Badoglio como un traidor del fascismo.

Durante el gobierno de Badoglio, en Torino, el general Adami Rossi, comandante de la defensa territorial de la ciudad, en varias ocasiones dio la orden a sus soldados de dispararle a los obreros durante las marchas (estr. 9). El Comité del Frente Nacional Popular le pidió al general entregar las armas al pueblo para que éste defendiera la ciudad de los nazis, como aconteció en otros lados, como en Cuneo, Ancona, y en el área de Gorizia. Sin embargo, Adami Rossi prefirió entregar la ciudad a los alemanes, huir y pasar a las órdenes de la República de Salò.

En junio 1944, el gobierno "no-político" de Badoglio dejó lugar a un gobierno de coalición más amplio, y la aventura de Badoglio se concluyó.

A nivel lingüístico observamos que el lenguaje es plenamente italiano, un italiano de registro coloquial, popular, que no teme las expresiones vulgares. No hay irregularidades sintácticas, cada estrofa constituye un periodo sintácticamente concluido, $y$, en general, las relaciones entre oraciones son más de coordinación que de subordinación.

Entre las coordinadas, se distinguen las que hacen un efecto de acumulación, por asíndeton (estr. 8) o por medio de la conjunción $e$ (estr. 2, 4, 6, 10), y las que se contraponen, por medio de las conjunciones adversativas ma e invece (estr. 3 , $4,6,8,11,13)$. En general, el texto está construido explotando mecanismos de

\footnotetext{
${ }^{9}$ Una canción en dialecto napolitano, el Canto allo scugnizzo, celebra este episodio de heróica resistencia popular.
} 
contraposición, no sólo por medio de oraciones coordinadas, sino también por medio de subordinación de tipo causal, como e allora (estr. 5, 7), y temporal, como mentre (estr. 6,10,13). Un tipo particular de argumentación es la que se expresa por medio de una oración condicional con se, para mostrar una paradoja (estr. 9) o para intensificar un argumento (estr. 15), o con la oración concesiva per quante moine facciate (estr. 14).

La oposición de fondo en todo el discurso es entre Badoglio (y el rey Vittorio, su "compinche") y noi ("nosotros"), quienes en la estr. 13 se autodefinen como los que mueren en los montes para defender a su país. A nivel textual la contraposición entre voi ("ustedes") y noi ("nosotros") se encuentra en el principio (estr. 1) y a finales de la canción (estr. 13, 14 y 15), para enmarcar la narración de los hechos con la expresión de un preciso juicio histórico-político sobre Badoglio por parte de un "yo" colectivo.

Insistente, la anáfora de la pregunta retórica Ti ricordi ("No recuerdas..."), que principia las estrofas $2,3,4,5,6$ y 12 , pone en evidencia las partes narrativas y contiene un elemento irónico, ya que los hechos evocados por la narración se están cuestionando a nivel implícito (por medio de relaciones sintácticas de las que se infiere una contraposición, como expuesto arriba) y explícito. Observamos también la apóstrofe inicial $O$ Badoglio, estr. 1, que se repite en la última estrofa de la canción, $T u$, Badoglio (estr. 15), junto con la anáfora con variatio de la locución coloquial-vulgar rompere i coglioni: ci hai giá rotto abbastanza i coglion, estr. 1, ci hai rotto i coglioni, estr. 15 (que decidí traducir pragmáticamente en ambos casos, recorriendo al español coloquial de México: "ya nos tienes hasta la madre", en el primer caso, y "nos traes hasta el huevo", en el segundo, para rendir el climax de ci ha rotto le tasche / ci hai rotto $i$ coglioni). Estas apóstrofes fungen de premisa y de conclusión para la evocación de los hechos, constituyendo un cuestionamiento explícito al rol político-militar desempeñado por el mariscal Badoglio durante la guerra.

Otros ejemplos de registro coloquial en la canción son degno compare ("digno compinche", estr. 1), gran bel porcacción ("muy, pero muy marrano" estr. 2), prendevi la mancia ("te sacaste el pilón", estr. 4), mandati al macello y farti più bello ("que mandaste al matadero", "lucirte", estr. 5), ci sono i quattrini ("hay mucho dinero", estr. 6), calava i calzon ("se bajaba el pantalón", en el sentido de "se rendía, mostraba su debilidad", estr. 10), crepiamo, imbecilli, lasciarci fregar ("reventamos", con una connotación intensiva y despectiva; "imbéciles"; "dejarnos joder", estr. 13) y ci ha rotto le tasche ("nos tiene hasta el gorro", estr. 15).

Observamos también la presencia de un tipo particular de anáfora que ya hemos observado en Bella ciao: la que ocurre entre una palabra al final de una estrofa y otra al principio de la estrofa siguiente: así entre la estr. 7 y la 8 (e si 
aspetta la buona occasion / L'occasione é arrivata) y entre la estr. 10 y la 11 (e Vittorio calava i calzon / I calzoni li hai calati). Este tipo de anáfora, con una función de ayuda a la memoria, es muy frecuente en la canción y en la poesía popular, como en todos los modos de la tradición oral.

Finalmente se notan unos ejemplos de topicalización, muy típicos del italiano coloquial hasta la fecha, que se manifiestan con un orden marcado de las palabras en la oración, como en gli squadristi li hai richiamati, gli antifascisti li hai messi in galera (estr. 8) o al principio de la estr. 11, I calzoni li hai calati: se trata de un mecanismo sintáctico que pone en evidencia el complemento directo, desplazándolo en el primer lugar de la oración.

También esta canción despertó sensibilidades mucho más adelante, en la historia de la Italia democrática y republicana, como relata este testimonio del diario italiano L'Unità del 9 de abril de 1966:

El día 8 de abril, el juez de Ravenna condenó al joven cantante Antonio Ricci di Villanova di Bagnacavallo a pagar una multa de diez mil liras. Esto porque Ricci, junto con el locutor Enzo Fabbri, había puesto en escena, el año precedente, un espectáculo sobre la Resistencia italiana y lo había representado en varias localidades de Romagna. En septiembre, en el caserío de San Pietro in Campiano, durante el recital hubo una fuerte reacción por el comandante de los carabineros al cantar Ricci La Badoglieide (a pesar de que dicha canción ya estaba grabada en disco). ${ }^{10}$

La música de esta canción ha sido adaptada muchas veces a diferentes canciones de fábrica: la última estrofa, con los nombres cambiados según la ocasión, está presente en todas las versiones. Éstos y muchos otros cantos populares nos muestran la verdadera cara de la guerra: su ironía desenmascara la hipocresía de los discursos triunfalistas del poder de ayer y hoy, poniendo al desnudo los verdaderos intereses políticos y económicos que hay detrás de una guerra, el oportunismo y el cinismo de los gobernantes, y las falsedades de la propaganda, para revelar la cara de dolor y muerte común a todas las guerras.

Esta canción es también un testimonio de lo profundo que fue la herida del fascismo y de la guerra civil en Italia, y del peso que estos acontecimientos tuvieron en la vida democrática de la Italia de la posguerra: el plan Marshall y la Guerra Fría, por un lado, y la difícil reconciliación nacional, que se resolvió en la reintegración de los ex fascistas en sus puestos, por el otro. Esto causó amargas decepciones entre los partisanos, y en muchos casos los impulsó a

${ }^{10}$ También esta cita se encuentra en el sitio web arriba mencionado (n. 6). 
enrolarse como voluntarios en las guerras antiimperialistas, desde Yugoslavia hasta Corea y Vietnam. ${ }^{11}$

\section{Bibliografia}

BERMANI, Cesare. 1999. Introduzione alla storia orale. Storia, conservazione delle fonti e problemi di metodo. Roma: Odradek.

Bosio, Gianni. 1998², primera edición 1975. L'intellettuale rovesciato. Interventi e ricerche sulla emergenza d'interesse verso le forme di espressione e di organizzazione "spontanee" nel mondo popolare e proletario (gennaio 1963-agosto 1971). A cura di C. Bermani. Milán: Jaca Book / Istituto Ernesto de Martino.

FALABRINO, Gian Luigi. 1994. I comunisti mangiano i bambini. La storia dello slogan politico. Milán: Vallardi.

http://www.vocidimezzo.it

MERCuRI, Lamberto y Carlo TuZzı. 1962. Canti politici italiani 1793-1945. Roma: Editori Riuniti.

PRINCIPE, Igor. "La storia del novecento italiano raccontata dalle canzonette". http:/www.cronologia.it/storia/tabello/tabe1556.htm

RaVAGLI, Vitaliano y Wu MrNG. 2000. Asce di guerra. Milán: Marco Tropea.

VETTORI, Giuseppe. 1975. Il folk italiano. Canti e ballate popolari. Roma: Newton Compton.

${ }^{11}$ Sobre este fenómeno social de la posguerra, véase V. Ravagli y Wu Ming (2000). 